\title{
Astragalus membranaceus-Polysaccharides Ameliorates Obesity, Hepatic Steatosis, Neuroinflammation and Cognition Impairment without Affecting Amyloid Deposition in Metabolically Stressed APPswe/PS1dE9 Mice
}

\author{
Yung-Cheng Huang ${ }^{1,2,+}$, Huey-Jen Tsay ${ }^{3,+}$, Mei-Kuang Lu ${ }^{4}$, Chien-Hung Lin ${ }^{3}$, Chih-Wen Yeh ${ }^{3}$, \\ Hui-Kang Liu ${ }^{4,5, *}$ and Young-Ji Shiao ${ }^{4,6, *}$ (D) \\ 1 Department of Physical Medicine and Rehabilitation, Cheng Hsin General Hospital, Taipei 11220, Taiwan; \\ jeremy0681@gmail.com \\ 2 Program in Molecular Medicine, School of Life Sciences, National Yang-Ming University, Taipei 11221, Taiwan \\ 3 Institute of Neuroscience, Brain Research Center, School of Life Science, National Yang-Ming University, \\ Taipei 11221, Taiwan; hjtsay@ym.edu.tw (H.-J.T.); whitebrake@hotmail.com (C.-H.L.); \\ flow5168@hotmail.com (C.-W.Y.) \\ 4 National Research Institute of Chinese Medicine, Ministry of Health and Welfare, Taipei 11221, Taiwan; \\ mklu@nricm.edu.tw \\ 5 Program in Clinical Drug Development of Chinese Herbal Medicine, Taipei Medical University, \\ Taipei 11031, Taiwan \\ 6 Institute of Biopharmaceutical Science, National Yang-Ming University, Taipei 11221, Taiwan \\ * Correspondence: hk.liu@nricm.edu.tw (H.-K.L.); yshiao@nricm.edu.tw (Y.-J.S.); \\ Tel.: +886-2-2820-1999 (ext. 3711) (H.-K.L.); +886-2-2820-1999 (ext. 4171) (Y.-J.S.) \\ + These authors contributed equally to this work.
}

Received: 15 November 2017; Accepted: 15 December 2017; Published: 18 December 2017

\begin{abstract}
Astragalus membranaceus is commonly used in traditional Chinese medicine for strengthening the host defense system. Astragalus membranaceus-polysaccharides is an effective component with various important bioactivities, such as immunomodulation, antioxidant, anti-diabetes, anti-inflammation and neuroprotection. In the present study, we determine the effects of Astragalus membranaceus-polysaccharides on metabolically stressed transgenic mice in order to develop this macromolecules for treatment of sporadic Alzheimer's disease, a neurodegenerative disease with metabolic risk factors. Transgenic mice, at 10 weeks old prior to the appearance of senile plaques, were treated in combination of administrating high-fat diet and injecting low-dose streptozotocin to create the metabolically stressed mice model. Astragalus membranaceus-polysaccharides was administrated starting at 14 weeks for 7 weeks. We found that Astragalus membranaceus-polysaccharides reduced metabolic stress-induced increase of body weight, insulin and insulin and leptin level, insulin resistance, and hepatic triglyceride. Astragalus membranaceus-polysaccharides also ameliorated metabolic stress-exacerbated oral glucose intolerance, although the fasting blood glucose was only temporally reduced. In brain, metabolic stress-elicited astrogliosis and microglia activation in the vicinity of plaques was also diminished by Astragalus membranaceus-polysaccharides administration. The plaque deposition, however, was not significantly affected by Astragalus membranaceus-polysaccharides administration. These findings suggest that Astragalus membranaceus-polysaccharides may be used to ameliorate metabolic stress-induced diabesity and the subsequent neuroinflammation, which improved the behavior performance in metabolically stressed transgenic mice.
\end{abstract}


Keywords: cognitive dysfunction; Astragalus-polysaccharides; glia; metabolic stresses; amyloid plaque; Alzheimer's disease

\section{Introduction}

Sporadic Alzheimer's disease (AD) is a metabolic disease relative to impairments in brain insulin signaling and energy metabolism, which lead to increased oxidative stress, inflammation, and aggravation of insulin resistance [1]. Epidemiological research suggests that type II diabetes mellitus (T2DM) increases the risk of AD. Multiple possible links between T2DM and sporadic AD including insulin resistance, inflammation, and oxidative stress have been proposed. Therefore, metabolic stress may directly contribute to loss of neuron and synaptic connection, tau hyperphosphorylation, and amyloid- $\beta(\mathrm{A} \beta)$ accumulation in $\mathrm{AD}$ [1]. In addition, chronic inflammation mediated by over activation of microglia and/or astrocytes in brain is involved in AD pathogenesis [2].

In our previous studies, we found that obesity, hyperglycemia, hepatic steatosis, A $\beta$ plaque burdens and cerebrovascular inflammation in APPswe/PS1 $\triangle E$ 9 (APP/PS1) transgenic mice is accelerated by the combination of high-fat diet (HFD) and a low-dose injection of streptozotocin (STZ) (i.e., HFSTZ AD mice) [3-5]. In those studies, we found an interplay between genetic background of AD and HFSTZ-induced metabolic stress. Moreover, HFSTZ aggravated vascular inflammation, astrocyte activation, and impairment of cerebral glucose metabolism and daily living activity in APP/PS1 mice.

The root of Astragalus membranaceus is an herb commonly used in traditional Chinese medicine for strengthening the host defense system [6]. The bioactive constituents in the dried root of A. membranaceus are complicated, containing polysaccharides, flavonoids, astragalosides, etc. [7]. A. membranaceus polysaccharides (APS) was identified as one of the major active ingredients responsible for the bioactivities, including antioxidant, immunomodulation, anti-inflammation, anti-diabetes, anti-atherosclerosis, hematopoiesis, hepatoprotection and neuroprotection [8-11]. Moreover, APS has also been found to decrease the body weight and blood glucose, and improve the insulin sensitivity in the muscle of HFD plus STZ-induced T2DM rats [12] and mice [13], and improvement of early diabetic nephropathy in T2DM rats [14]. However, the effect of APS on metabolic stressed AD model has not yet been investigated.

In this study, we aim to examine the effect of APS on metabolic stress-aggravated pathological progression of AD. We hypothesized that APS may ameliorate diabesity-associated metabolic changes on cerebral and hepatic inflammation that in turn reduce neuroinflammation-related pathologies. We examined blood glucose, insulin, homeostasis model assessment of insulin resistance (HOMA-IR), Leptin, body weight, epididymal fat, hepatic steatosis, $\mathrm{A} \beta$ burden, glial activation, and nesting behavior in HFSTZ-APP/PS1 mice.

\section{Results}

\subsection{Characterization of Astragalus membranaceus Polysaccharides (APS)}

For studying the effects of APS on metabolically stressed AD, APS was isolated. Lyophilized dried roots of Astragalus membranaceus were extracted with water and precipitated with $95 \%$ ethanol. After lyophilization, a crude brownish polysaccharide denoted as APS was obtained. Yield of APS was determined as $3.47 \pm 0.08 \%$. The molecular mass distribution of APS was determined by chromatography (Figure 1). The result showed that there were five populations of APS with molecular weight range from 2676.00 (peak 1) to $0.86 \mathrm{kDa}$ (peak 5). The major polysaccharide population was low-molecular-weight polysaccharides $(5.14 \mathrm{kDa}$, peak 4$)$ in the percent area 65.78 . The major monosaccharide composition of APS is fucose:myo-inositol:fructose:sorbitol:glucose in the ratio of 1:1.4:2.1:13.7:91.5. 


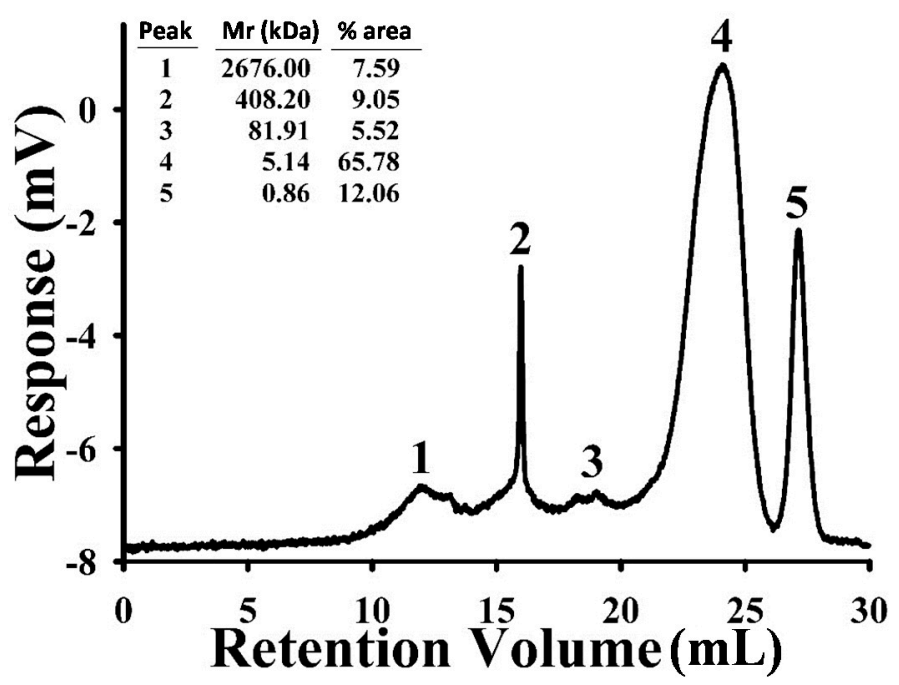

Figure 1. The composition of Astragalus membranaceus Polysaccharides (APS). Carbohydrate solution was injected onto the Size-Exclusion Chromatography (SEC) column and was eluted by deionized water. SEC signal detection (response, $\mathrm{mV}$ ) was performed using a ViscoTek model TDA-3-1 relative viscometer (Viscotek, Houston, TX, USA). Sodex P-82 series (Showa Denko America, New York, NY, USA) containing polymaltotriose with molecular weights of $78.8 \times 10^{4}, 40.4 \times 10^{4}, 21.2 \times 10^{4}$, $4.73 \times 10^{4}$, and $1.18 \times 10^{4}$ Daltons $(\mathrm{Da})$ was used as authentic standard. The molecular weight $(\mathrm{Mr}$ $(\mathrm{kDa}))$ and area percentage (\% area) of each peak was calculated and displayed at upper left corner.

\subsection{APS Ameliorates HFSTZ-Induced Insulin Resistance and Hyperleptinemia}

APS are the key components of Astragalus membranaceus, which capable to improve insulin resistance and reduced blood glucose is widely used in Traditional Chinese Medicine [15]. Whether APS ameliorates hyperglycemia of HFSTZ AD mice was evaluated. HFSTZ induced a significant increase level of fasting blood glucose in APP/PS1 transgenic mice after 4 weeks administration of HFD (i.e., 2 weeks after STZ injection) (Figure 2a). There is only transient reduction on HFSTZ-induced hyperglycemia during the first three weeks after APS administration (Figure 2a). At the 11th week, however, the fasting blood glucose was not significant different between HFSTZ and normal chow diet (NCD) groups (Figure 2a,b). Oral glucose tolerance test (OGTT) was performed at 10 weeks post HFD administration. The result showed that APS reduced the HFSTZ-induced glucose intolerance (Figure 2c). The significant difference was confirmed by comparing the lower area under the curve (AUC) of glucose tolerance assay (Figure 2d). For serum insulin concentration, we observed that HFSTZ-induced hyperinsulinemia (increased insulin level) and insulin resistance (elevated HOMA-IR) were mitigated by APS (Figure 2e,f). For serum leptin concentration, we observed that HFSTZ-induced hyperleptinemia (increased leptin level) was also alleviated by APS (Figure 2g). 
a
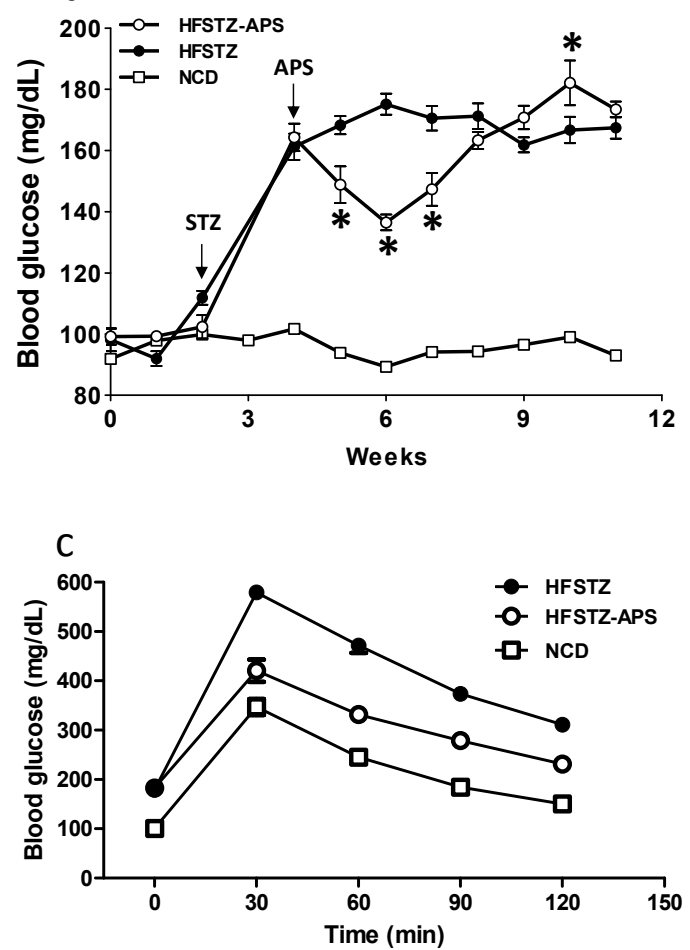

b
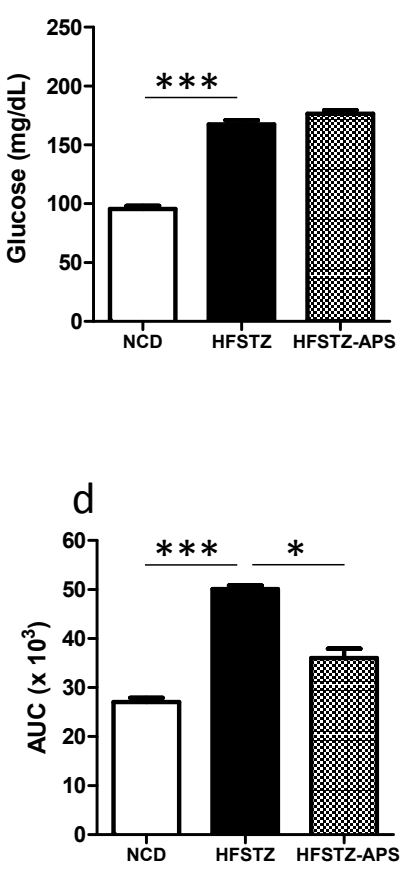
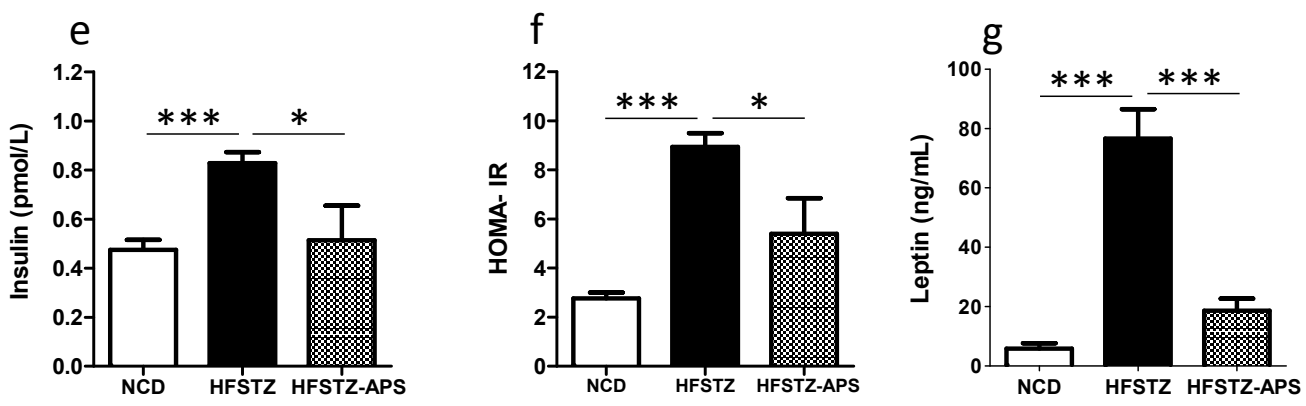

Figure 2. APS ameliorated HFSTZ-impacted glycemic control. Three groups of APP/PS1 mice: normal chow diet (NCD) $(n=6)$, high fat diet plus streptozotocine (HFSTZ) $(n=7)$ or HFSTZ plus APS (HFSTZ-APS) $(n=6)$ are examined. (a) Fasting glucose levels detected every week; (b) Fasting glucose levels detected at 11 weeks after dietary manipulation; (c) Oral glucose tolerance testing was performed 10 weeks after dietary manipulation; (d) Area under curve (AUC) values of panel c; (e) Fasting insulin; (f) homeostasis model assessment of insulin resistance (HOMA-IR), and (g) leptin were determined at 11 weeks after dietary manipulation. Bars represent the mean \pm SEM. ${ }^{*} p<0.01$ and ${ }^{* * *} p<0.001$, significant difference from HFSTZ group.

\subsection{APS Ameliorates HFSTZ-Induced Obesity and Hepatic Steatosis, but Not Adipocyte Hypertrophy}

As shown in Figure 3a, HFSTZ-induced obesity was significantly reduced by the administration of APS. At the end of experiment, the epididymal fat weight was significantly increased and adipocyte size was significantly enlarged in HFSTZ mice as compared with NCD mice. However, APS was ineffective on reducing this adipocyte hypertrophy including epididymal fat mass, and adipocyte number and size (Figure $3 b-d)$. 
a

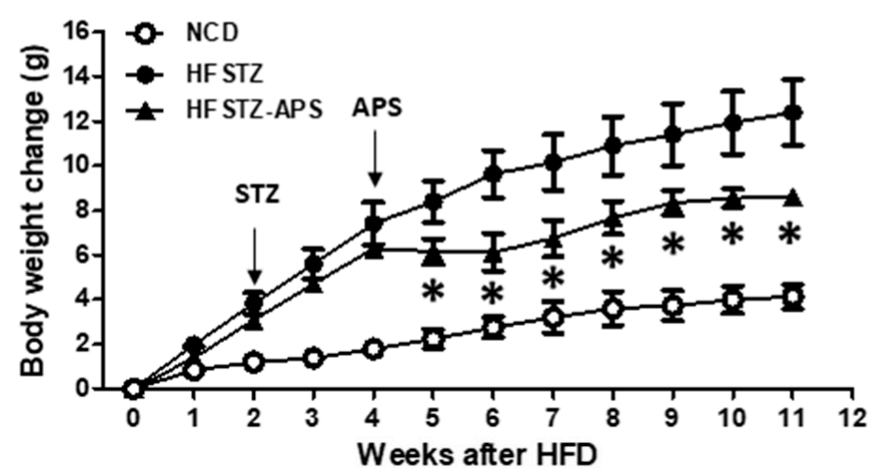

b

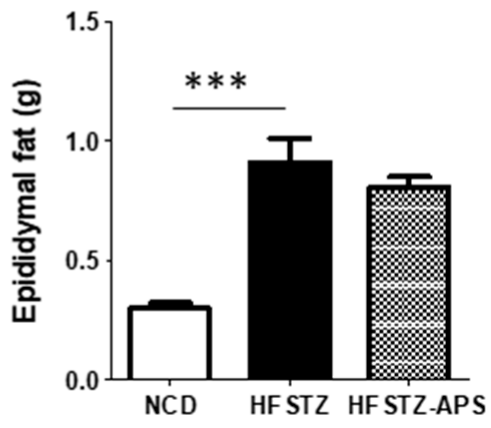

C

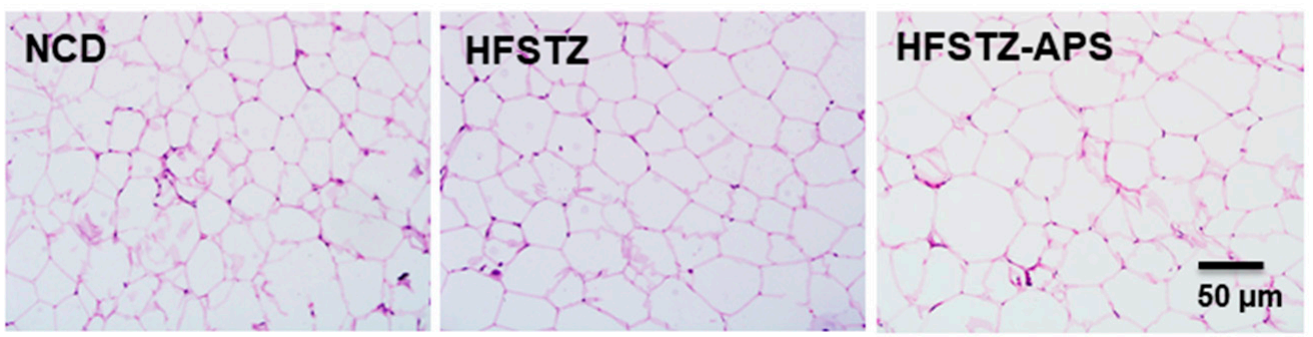

d
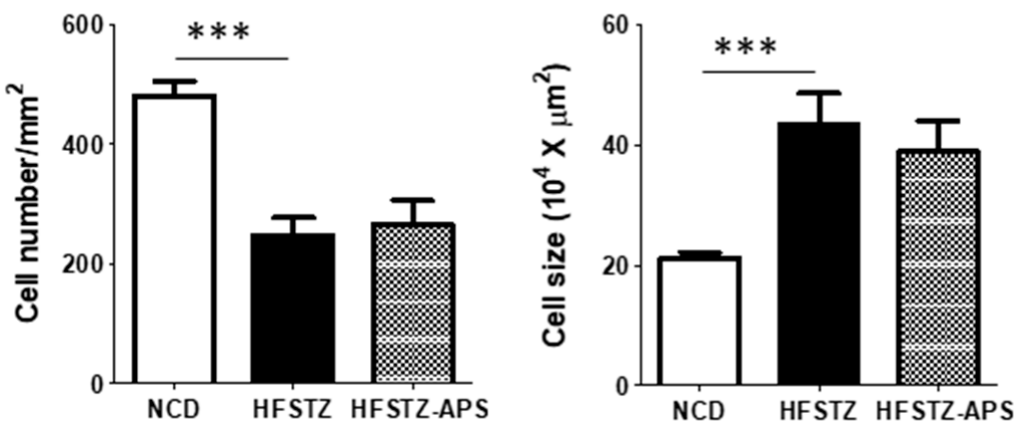

Figure 3. APS recovered the body weight increase mediated by the treatment of HFSTZ. Three groups of APP/PS1 mice: NCD $(n=6)$, HFSTZ $(n=7)$ or HFSTZ-APS $(n=6)$ are examined. (a) Body weights were recorded every week; (b) The mass of epididymal fat tissue was determined; (c) Representative histological microphotographs of hematoxylinand eosin (HE)-stained epididymalfat sections were shown (scale bar, $50 \mu \mathrm{m}$ ); (d) Adipocyte number and size were measured by ImageJ. Bars represent the mean \pm SEM of atleast three independent experiments. Bars represent the mean \pm SEM. ${ }^{*} p<0.01$ and *** $p<0.001$, significant difference from HFSTZ group.

In hematoxylinand eosin (HE)-stained liver section, severe vacuolation of hepatocytes was observed in HFSTZ mice (Figure 4a). We found that APS significantly reduce this vacuolation of hepatocytes. Consistently, HFSTZ-increased liver triacyl glycerol (TG) content was mitigated by APS (Figure $4 b$ ). 
a
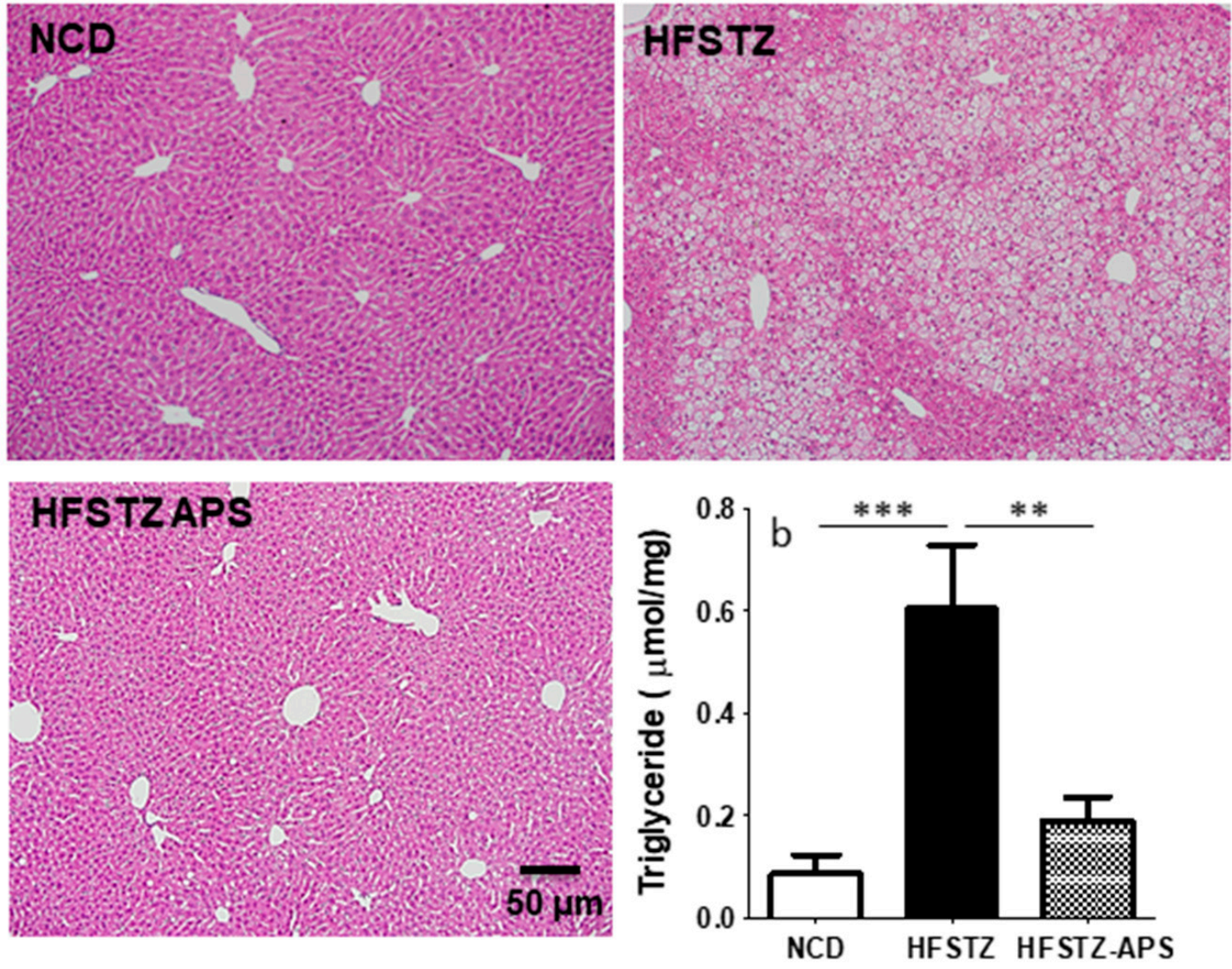

Figure 4. APS ameliorated HFSTZ-induced hepatic steatosis. Three groups of APP/PS1 mice: $\operatorname{NCD}(n=6)$, HFSTZ $(n=5)$ or HFSTZ-APS $(n=7)$ are examined. (a) Representative images of HE-stained liver sections (scale bar, $50 \mu \mathrm{m}$ ) were shown. (b) Hepatic triacyl glycerol (TG) contents were quantified. Bars represent the mean \pm SEM. ${ }^{* *} p<0.01$ and ${ }^{* * *} p<0.001$, significant difference from HFSTZ group.

\subsection{APS Did not Significantly Reduce HFSTZ-Aggravated Cerebral A $\beta$ Deposition}

BSB ((trans, trans),-1-bromo-2,5-bis-(3-hydroxycarbonyl-4-hydroxy) styrylbenzene) was used to stain senile plaque and the effect of APS on plaque accumulation was analyzed. The result did not show any significant effect of APS on the burden of cerebral A $\beta$ plaques in HFSTZ mice (Figure $5 a, b$ ). Using an enzyme-linked immunosorbent assay (ELISA) assay to determine the level of A $\beta$ in both cerebrum and serum. The result, again, did not show any significant effect of APS on the level of A $\beta$ (Figure $5 c, d$ ). 
a
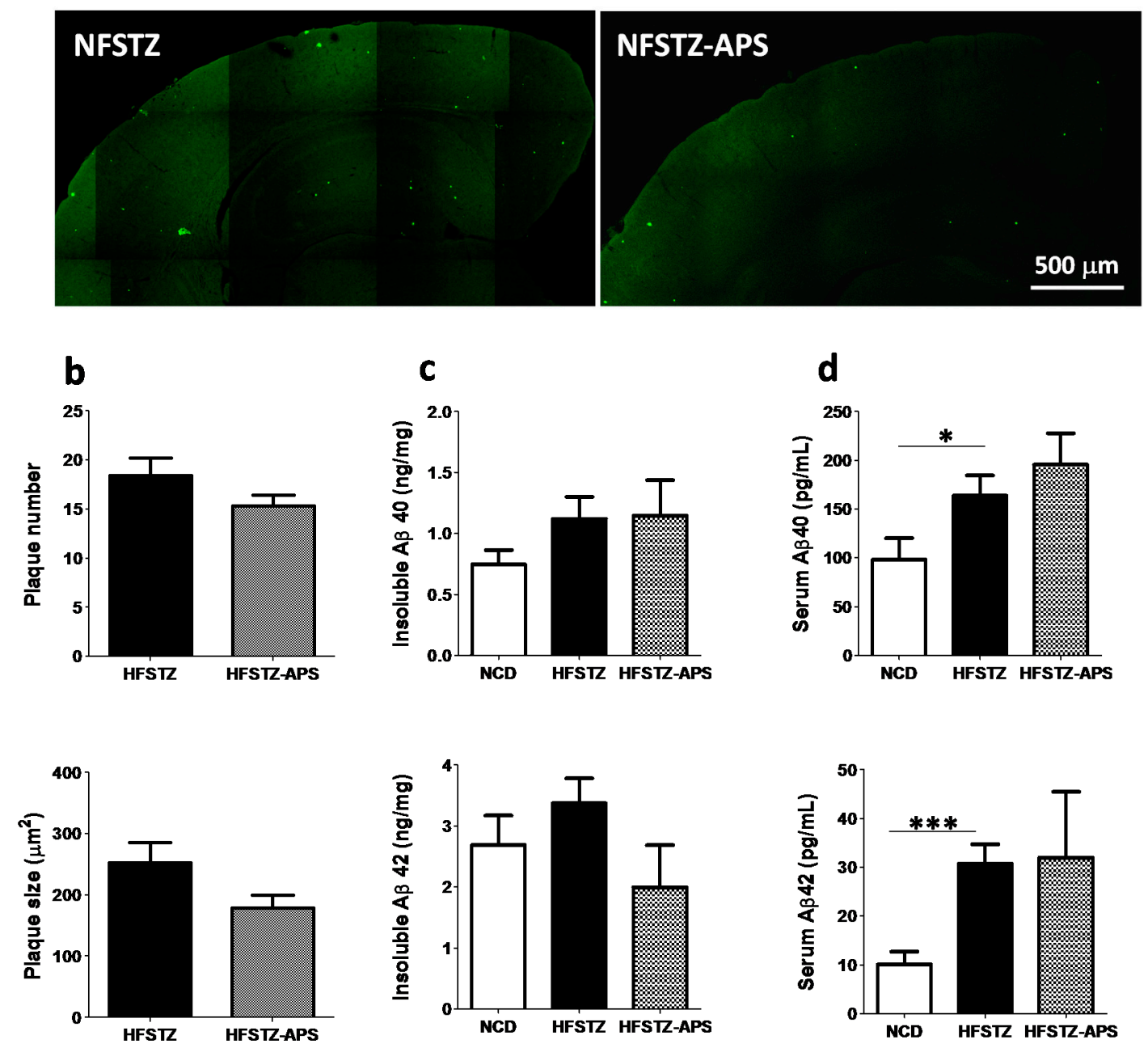

Figure 5. APS did not ameliorate HFSTZ-aggravated cerebral A $\beta$ deposition and serum A $\beta$. APP/PS1 mice were treated with HFSTZ $(n=5)$ or HFSTZ-APS $(n=6)$; (a) Representative images of 1-bromo-2,5-bis-(3-hydroxycarbonyl-4-hydroxy) styrylbenzene (BSB)-positive plaques in the cerebral cortex of HFSTZ and HFSTZ-APS mice (scale bar, $500 \mu \mathrm{m}$ ); (b) Plaque size and plaque number in a single hemisphere were calculated using Metamorph analysis software. APP/PS1 mice were treated with NCD $(n=14)$, HFSTZ $(n=15)$ or HFSTZ-APS $(n=7)$; (c) Levels of soluble and insoluble form $A \beta 40$ and $A \beta 42$ in cerebral cortex were measured by enzyme-linked immunosorbent assay (ELISA); (d) The Serum $A \beta 40$ and $A \beta 42$ levels were measured using ELISA. Bars represent the mean \pm SEM of four independent experiments. Data are shown as mean \pm SEM. ${ }^{*} p<0.05$, and ${ }^{* *} p<0.001$, significant difference from HFSTZ group.

\subsection{APS Diminished HFSTZ-Activated Plaque-Associated Astrocytes and Microglia}

The fluorescence intensity of glial fibrillary acidic protein (GFAP) was determined to assess the reactivity of plaque-associated astrocytes in an area with 8 times the diameter of the plaques which the astrocyte surrounded. The result shows that APS significantly diminished the reactivity of plaque-associated astrocytes (Figure 6a-c). A scatter plot of plaque size and GFAP area from 72 and 64 plaques in HFSTZ and HFSTZ-APS mice, respectively, was plotted to reveal the change of the activated astrocytes in the vicinity of plaque after APS treatment. The result showed that the APS treatment diminished HFSTZ-induced activation of plaque-associated astrocytes (Figure 6d). Linear regression for HFSTZ group is $y=1.25 x+470.6, R^{2}=0.13$, for HFSTZ-XZD group is $y=1.35 x+78.39, R^{2}=0.37$ 
( $p=0.88$ for difference in slops; $p<0.001$ for difference in intercept), suggesting that the effect is plaque size-independent.
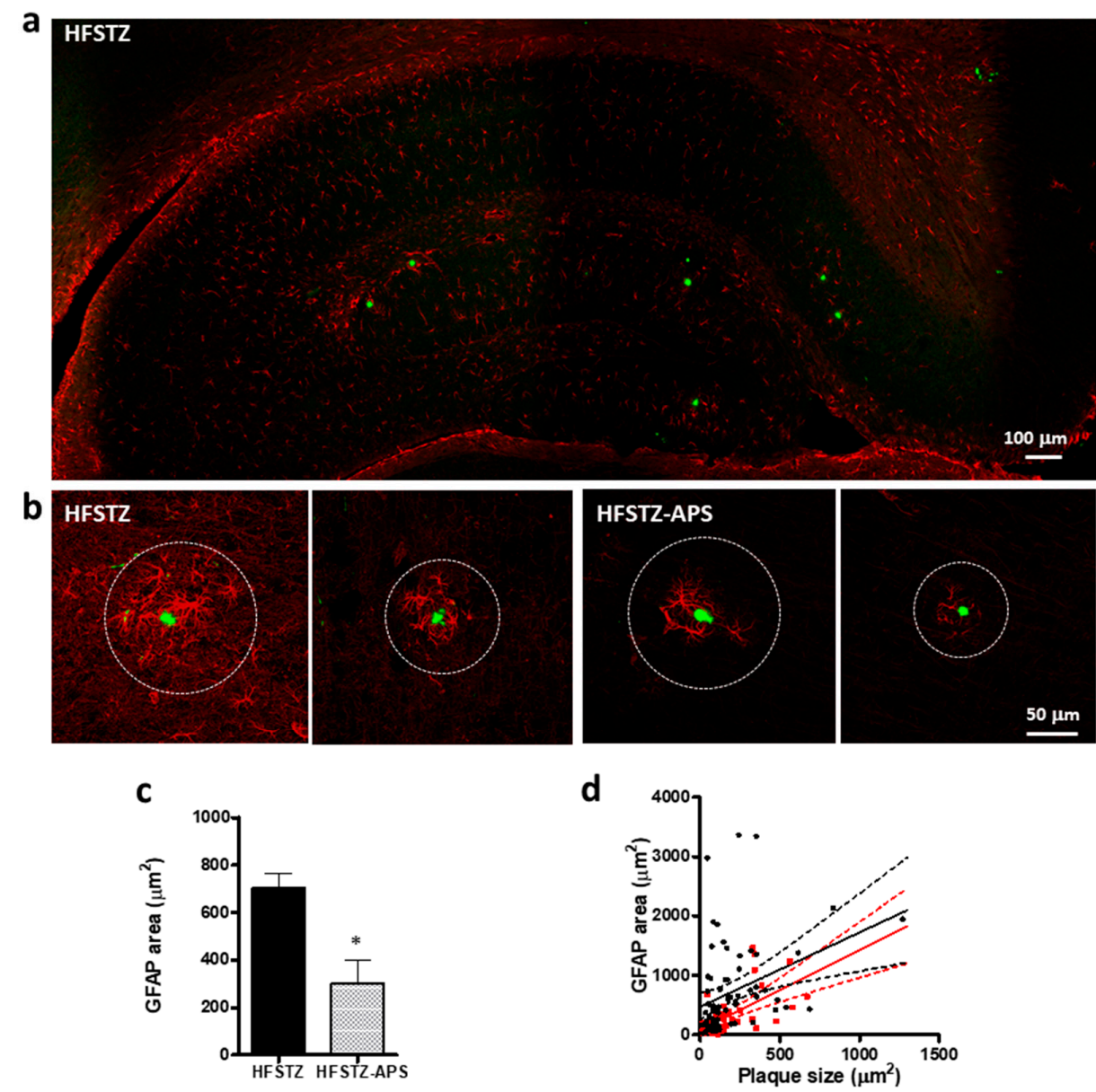

Figure 6. APS ameliorated HFSTZ-augmented activation of astrocytes in the vicinity of plaques. APP/PS1 mice were treated with HFSTZ $(n=4)$ or HFSTZ-APS $(n=4)$. (a) Representative confocal images of plaque (green) and the plaque-associated astrocytes immunostained with anti-GFAP (red) antibody were shown. Scale bar, $100 \mu \mathrm{m}$; (b) Representative confocal images of two selected plaques (green) surrounded by GFAP-positive astrocytes (red) in HFSTZ and HFSTZ-APS mice. Scale bar, $50 \mu \mathrm{m}$; (c) GFAP-positive astrocyte area in the dotted circle indicated in panel b (8 time diameter of the surrounded plaque) in the vicinity of plaques in HFSTZ and HFSTZ-APS mice. Data are shown as mean \pm SEM. ${ }^{*} p<0.05$, significant difference from HFSTZ group; (d) The correlation of plaque size and GFAP positive area was analyzed by a scatter plot from 72 and 21 plaques in HFSTZ (black) and HFSTZ-APS (red) mice, respectively. Solid lines are linear regression lines and dashed lines are 95\% confidence intervals, $R^{2}=0.13$ for HFSTZ group and $R^{2}=0.17$ for HFSTZ-APS group.

Ionized calcium-binding adaptor molecule-1 (Iba-1) was used as microglia markers. We observed that microglia directly contacted the plaques. APS diminished the immunoreactivity of the Iba-1 that was associated with plaque. (Figure $7 \mathrm{a}, \mathrm{b}$ ). Plaque size and Iba-1 fluorescence intensity was analyzed by a scatter plot of 57 plaques to reveal the change of the activated plaque-associated microglia after APS treatment. The result showed that the APS treatment diminished HFSTZ-activated plaque-associated microglia (Figure 7c). Linear regression for HFSTZ group is $y=0.04 x+20.16, R^{2}=0.33$, for HFSTZ-APS group is $y=0.01 x+14.62, R^{2}=0.17$ ( $p=0.30$ for difference in slops; $p<0.01$ for difference in intercept), suggesting that the effect is plaque size-independent. 
a
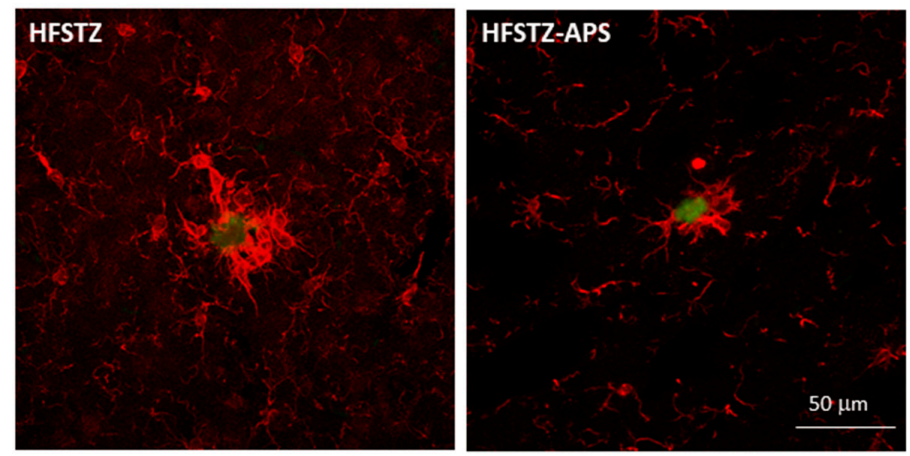

b

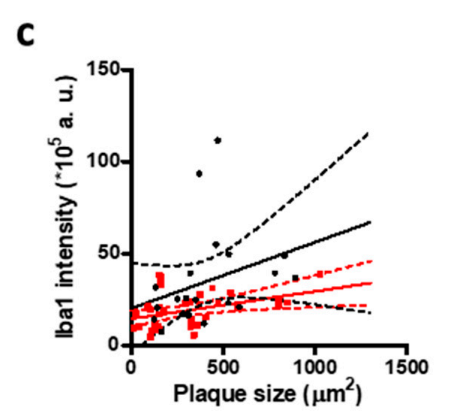

Figure 7. APS ameliorated HFSTZ-augmented activation of plaque-associated microglia. APP/PS1 mice were treated with HFSTZ $(n=4)$ or HFSTZ-APS $(n=4)$. (a) Representative images of the plaque-associated microglia immunostained with anti-Iba-1 antibody. Scale bar, $50 \mu \mathrm{m}$; (b) Immunoreactivity of Iba-1 in plaque-associated microglia in HFSTZ and HFSTZ-APS mice. Data are shown as mean \pm SEM. ${ }^{* *} p<0.001$, significant difference from HFSTZ group; (c) The correlation of plaque size and Iba1 intensity was analyzed by a scatter plot of plaque-associated microglia and plaque size from the selected plaques with vehicle (black) and APS (red) treatments. Solid lines is linear regression lines and dashed lines are $95 \%$ confidence intervals, $R^{2}=0.33$ for HFSTZ group and $R^{2}=0.61$ for HFSTZ-APS group.

\subsection{APS Ameliorated HFSTZ-Prolonged Time for Nest Construction in AD Mice}

A broad regions of brain has involved in nesting behavior of mice. The nesting task is therefore been used to evaluate cognition in $\mathrm{AD}$ animal models $[3,5,16]$. The result showed that the nesting score cannot tell the difference on the ability of nest construction among various mice groups. However, APS treatment recovered the prolonged nest constructing time for the HFSTZ mice (Figure 8).
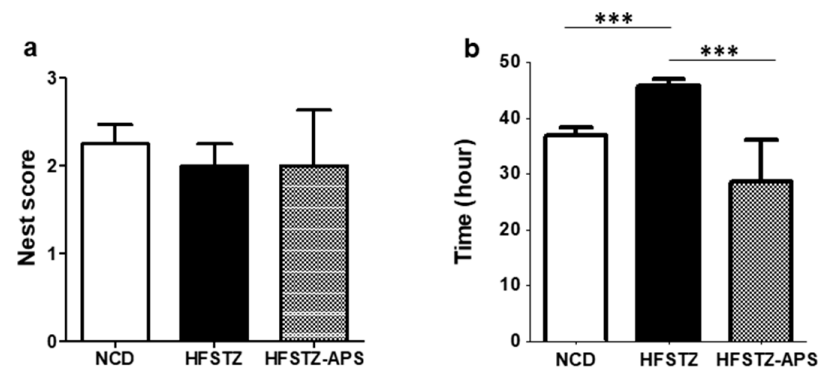

Figure 8. APS improved HFSTZ-prolonged nesting construction time. Nesting behavior for NCD $(n=7), \operatorname{HFSTZ}(n=6)$, and HFSTZ-APS $(n=3)$ mice groups were examined. (a) Nesting score $(\mathbf{b})$ Nestcomplete-construction time. Data are shown as mean \pm SEM. ${ }^{* * *} p<0.001$, significant difference from HFSTZ group. 


\section{Discussion}

Cerebrovascular inflammation and glucose hypometabolism were advised to associate with the cognitive impairment in diabesity [17]. Diet-induced peripheral metabolic changes have been suggested to be linked with amyloidosis [18]. Previously, we created an HFSTZ APP/PS1 animal model, which displayed diabesity and hepatic steatosis; elevated peripheral A $\beta$ level; enhanced A $\beta$ level, plaque burden, astrocyte activation, vascular inflammation, glucose hypometabolism in the cerebrum, and caused cognitive impairment in APP/PS1 mice [3,4]. In the present study, the effects of APS on the pathological changes stated above were studied. We found that HFSTZ-mediated diabesity, leptinemia, and hepatic steatosis were significantly alleviated by APS. However, APS did not affect adipocyte hypertrophy and only transient reduction of HFSTZ-induced hyperglycemia. In the brain, the A $\beta$-relative pathological changes were inspected. The result showed that APS reduced astrogliosis and microglia activation and ameliorated the nesting activity. Moreover, APS also alleviated HFSTZ-aggravated hepatic steatosis. However, there was no effect APS on serum level of $\mathrm{A} \beta$.

Following administration of APS (500 mg/ $\mathrm{kg} /$ day) for 7 weeks, there was no difference in fasting blood glucose level and mass of epididymal fat. However, it is clear that APS markedly reduced HFSTZ-altered body weight, fasting serum insulin level, MOMA-IR, serum leptin level, hepatic TG and hepatic steatosis. These results suggest that the effects of APS may be specific to vessel leading to anti-inflammation property, since diabetes and obesity have been indicated to induce hepatic oxidation and inflammation [19]. The increased leptin level and increased body weight might implicate that leptin resistance was induced by HFZTZ treatment (4). Recent study indicated that APS altered glucose metabolism and decreased insulin resistance in rat with STZ-induced diabetes [20]. In that work, the potential mechanism of APS on glucose and lipid metabolism, anti-oxidative, insulin resistance and memory deficit in diabetes was studied. In those works, APS (200-800 mg/ $\mathrm{kg} /$ day) was administrated for 8 weeks, and the fasting plasma glucose was significantly reduced after 8 weeks administration of APS as compared with the model group. In our present study, the fasting blood glucose was significantly reduced after 1-3 weeks, but not 4-7 weeks, administration of APS as compared with the model group. This different may be attributed to that the genetic background of APP/PS1 mice affects peripheral metabolism in the context of diabesity [4]. The similar result was also found in another previous work [5].

Liver has been suggested to be the major organ for plasma $A \beta$ clearance [21]. Therefore, the elevated peripheral A $\beta$ in HFSTZ mice might be attributed to hepatic steatosis. In our previous study [4], liver degradation play an important role on regulating the level of peripheral A $\beta$ which may in turn affect $A \beta$ drain out from CNS [21]. Our previous study suggested that obesity and hepatic steatosis were associated with elevated both serum $A \beta 42$ and $A \beta 40$, and the amount of serum $A \beta 42$ was reduced by the administration of Xuefu Zhuyu decoction, a traditional Chinese classical herbal formula used for promoting blood circulation and removing blood stasis $[4,5]$. In the present study, however, we found that HFSTZ-aggravated level of both serum $A \beta 42$ and $A \beta 40$ were not ameliorated by APS. This result suggests that A $\beta 42$-specific degradation in peripheral was not activated by APS, which does not promote blood circulation.

Growing evidence suggested that metabolic stressimpedes the functioning of the cerebrovascular neuroinflammation and $\mathrm{A} \beta$ deposition in AD mouse models. The diabesity-mediated cognitive impairments were suggested to be associated with altering the integrity and transport functions of blood-brain barrier (BBB), inducing oxidative stress and inflammation in the microcapillaries of central nervous system (CNS) [17] which subsequently results in $A \beta$ overproduction and/or insufficient clearance. In turn, the accumulated $A \beta$ may further induces neuroinflammation and neurotoxicity [2]. A defective vascular system was reported to reduce the drainage of parenchyma $A \beta$ [21]. Therefore, a vicious cycle between vascular impairment and $A \beta$-related neurotoxicity is formed during $A D$ pathogenesis progression. In the present study, HFSTZ-aggravated cerebral A $\beta$ 
deposition was not reduced by APS. The nesting activity of mice, however, is improved, suggesting that cerebral $A \beta$ deposition may not the major factor to influence nesting behavior.

Another histological feature of $\mathrm{AD}$ is the present and accumulation of reactive astrocytes and microglia around plaque, which is called gliosis or neuroinflammation [22]. Previously, APS has been found to be a promising therapeutic strategy for reducing inflammatory response [23] and possess anti-inflammatory activity [24-27]. Gliosis was observed to evaluate the effect of APS on ameliorating HFSTZ-induced neuroinflammation in our present study.

The roles of astrocytes such as glucose transportation; neuronal homeostasis and metabolism modulation; blood-brain barrier maintain; and microenvironment sensing are important for brain physiological function regulation. Thus, the over-activated astrocytes are functionally impaired [28]. $\mathrm{A} \beta$ plaque-associated reactive astrocytes displayed upregulating of glial fibrillary acidic protein (GFAP) expression and pro-inflammatory mediator production, suggesting the detrimental role of reactive astrocytes in AD [29]. Therefore, as shown in a previous study, A $\beta$ burden, microglial activation, and cognitive impairment may be decreased by suppressing astrocyte activation in a mouse model of AD [30]. Our present study found that APS significantly ameliorate HFSTZ-aggravated astrocyte reactivity in APP/PS1 mice, which is not correlated with plaque size, suggesting a direct effect of APS on astrocyte reactivity. We detected the reactivity of plaque-associated astrocytes by GFAP-positive area in 8 times diameter of the surrounded plaque, since the activated astrocytes did not contact with the plaque but surround plaque in a distance. For microglia, however, is directly contact with plaque. Therefore, the plaque-associated Iba-1-immunoreactivity was determined. In addition, this quantification cannot be replaced by Western Blotting since it is difficult to isolate plaque from the brains of mice.

Microglia mediate neurotoxicity in AD [2]. A $\beta$-activated microglia not only induced pro-inflammatory activity [31] but also contribute to plaque growth [32], suggesting that plaque-associated microglia is one of the mediators in $\mathrm{AD}$ pathology. Our present study found that APS significantly ameliorate the HFSTZ-aggravated plaque-associate microglia activation in APP/PS1 mice, which is independent with plaque size, suggesting the indirect effect of APS on microglia activity, and astrocyte activation may be the mediator. The effects of APS on HFSTZ-aggravated glial activation in APP/PS1 mice may include reducing astrocyte activation and mitigating microglia activation, which may affect nesting activity directly.

For mice, nesting behavior may be regarded as goal-directed. Several brain regions, including the hippocampus, are involved for nest construction [33]. Thus, nest construction task can be employed to evaluate the daily living activity of mice [34]. Previously, we have indicated that APP/PS1 mice were impaired in nesting construction by increasing the nesting construction time, but not the nest score [3]. These results may be responsible of that $16 \mathrm{~h}$ for nest scoring cannot differentiate the behavior impairment between NCD-APP/PS1 mice and HFSTZ-APP/PS1 mice. Therefore, the nest-completing time was employed. Our present results suggest that APS significantly decreased the nesting construction time, but not the nest score, in HFSTZ-APP/PS1 mice. This result suggested that APS recovered the nesting construction time prolonged by HFSTZ treatment.

\section{Materials and Methods}

\subsection{Isolation of Polysaccharides}

Lyophilized dried roots of Astragalus membranaceus were extracted with $80^{\circ} \mathrm{C}$ water $(1: 20(w / w))$ for $6 \mathrm{~h}$ twice. After cooling, four volumes of $95 \%$ ethanol are added into the extract to precipitate polysaccharides overnight at $4{ }^{\circ} \mathrm{C}$. The precipitated were collected by centrifugation. After lyophilization, a crude brownish polysaccharide denoted as APS was obtained. 


\subsection{Size-Exclusion Chromatography (SEC)}

Carbohydrate solution $(1 \mathrm{mg} / \mathrm{mL}$ ) was filtered through a $0.22 \mu \mathrm{m}$ filter (Millipore, MA, USA) and then injected onto the SEC column. The flow rate was $0.5 \mathrm{~mL} / \mathrm{min}$, with deionized water being used as the eluent. A calibration curve was constructed using an authentic standard, Sodex P-82 series (Showa Denko America, New York, NY, USA) containing polymaltotriose with molecular weights of $78.8 \times 10^{4}, 40.4 \times 10^{4}, 21.2 \times 10^{4}, 4.73 \times 10^{4}$, and $1.18 \times 10^{4}$ Daltons (Da). The TriSec software program was used for the acquisition and analysis of Viscotek data. SEC signal detection was performed using a ViscoTek model TDA-3-1 relative viscometer (Viscotek).

\subsection{Hydrolysis and Monosaccharides Compositional Determination of the Polysaccharide}

One milligram of polysaccharide was hydrolyzed with $6 \mathrm{~N} \mathrm{HCl}$ at $80{ }^{\circ} \mathrm{C}$ in a heating block for 6-8 $\mathrm{h}$. The mixture was cooled and evaporated to remove the acid, resuspended in milli-Q water and passed through a Millipore-GX nylon membrane before analysis. Monosaccharides of polysaccharide hydrolysates were separated on a high-performance anion-exchange chromatographic (HPAEC) system (Dionex, Sunnyvale, CA, USA) and an anion-exchange column (Carbopac PA-10, $4.6250 \mathrm{~mm}$ ). The analysis of monosaccharides was carried out at an isocratic $\mathrm{NaOH}$ concentration of $18 \mathrm{mM}$ at ambient temperature.

\subsection{Animal Management and Administration}

APP/PS1double transgenic mice (No. 005864, Jackson Laboratory, Bar Harbor, ME, USA) express a chimeric mouse/human APP (Mo/HuAPP695swe) and a mutant human presenilin 1 (PS1-dE9) both directed to CNS neurons [35]. They were bred in standard animal house (female C57BL/6 mice and male APP/PS1 mice). Animals were housed under $24 \pm 1{ }^{\circ} \mathrm{C}$ temperature and $55-65 \%$ humidity with a 07:00-19:00 light-dark cycle. The Institutional Animal Care and Use Committee at the National Research Institution of Chinese Medicine approved the animal protocol (IACUCNo: 103-417-2 (103.12.26), 104-417-1 (103.12.21) and 105-417-1 (104.08.10)). Guide for the Care and Use of Laboratory Animals (NIH) was followed for all experimental procedures involving animal and their care.

\subsection{Metabolic Stress Induction}

HFSTZ Mice were created by feeding a high-fat diet and injecting single-dose STZ [3-5]. Briefly, 10 week-old mice were fed a HFD (60\% energy from fat; TestDiet, St. Louis, MO, USA) with water ad libitum. For control, a normal chow diet (NCD; MF-18, Oriental Yeast Co. Ltd., Tokyo, Japan) was used. Mice on HFD also received intraperitoneal injections of STZ (50 mg/ $\mathrm{kg}$, in $0.1 \mathrm{M}$ citrate buffer, pH 4.5) 2 weeks after HFD initiated (HFSTZ group). On the contrary, NCD mice were injected with vehicle ( $0.1 \mathrm{M}$ citrate buffer, $\mathrm{pH} 4.5)$. The HFD continued for 11 weeks of HFD manipulation. To evaluate the effect of APS on ameliorating the impairment in HFSTZ mice, APS $(500 \mathrm{mg} / \mathrm{kg})$ was orally administrated twice per day for 7 weeks after 4 weeks of HFD administration. The body weight and blood glucose were recorded every week after dietary manipulations except the week for STZ injection.

\subsection{Blood Glucose Analysis and Oral Glucose Tolerance Test}

After fasted for $16 \mathrm{~h}$, Oral Glucose Tolerance Tests (OGTTs) were performed. The mice were then given a glucose solution ( $3 \mathrm{~g} / \mathrm{kg}$; Sigma Aldrich, St. Louis, MO, USA) by oral gavage. Blood is drawn at intervals of $30 \mathrm{~min}$ for measurement of glucose. Blood glucose was measured using a glucometer (Bioptik Technology, Taipei, Taiwan).

\subsection{Tissue Sample Collection}

On the end of dietary manipulations, mice were deep anesthetized by injected with $80 \mathrm{mg} / \mathrm{kg}$ sodium pentobarbital intraperitoneally. Blood sample was collected by the cardiac puncture and 
then sacrificed by transcardial perfusion with $50 \mathrm{~mL}$ saline. Brain, liver and epididymal fat tissues were collected.

\subsection{Leptin and Insulin Analysis}

Serum leptin were measured by ELISA (BioVision, Miltipas, CA, USA). Plates were read at a wavelength of $450 \mathrm{~nm}$. Serum insulin levels were determined with an Insulin HTRF High Range kit (Cisbio, Codolet, France). The fluorescence intensities were measured on a SpectraMax M5 microplate reader (Molecular Devices, Sunnyvale, CA, USA). Homeostasis model assessment of insulin resistance scores were calculated as: HOMA-IR $=$ fasting blood glucose $(\mathrm{mM}) \times$ fasting insulin $(\mathrm{U} / \mathrm{mL} / 22.5)$.

\subsection{Hepatic Triglyceride Analysis}

Triglyceride (TG) in liver homogenate $(100 \mathrm{mg} / \mathrm{mL}, 5 \%$ NP-40) was measured with a TG quantification kit (BioVision, Milpitas, CA, USA). Plates were read at a wavelength of $570 \mathrm{~nm}$ using the TECAN GENios plate reader.

\subsection{Measurement of $A \beta$}

The cerebral cortex was homogenized in ice-cold homogenization buffer $(10 \mathrm{mM}$ Tris $\mathrm{HCl}$, $1 \mathrm{mM}$ ethylenediaminetetraacetic acid (EDTA), $0.25 \mathrm{M}$ sucrose, and $1 \mathrm{mM}$ phenylmethylsulfonyl fluoride (PMSF)) containing protease inhibitor cocktail tablets (Roche Diagnostics, Indianapolis, IN, USA). An equal volume of sodium dodecyl sulfate (SDS) solution (1\%, PBS with) was added to the homogenate. After centrifugation, the supernatant was collected (i.e., soluble A $\beta$ ). The insoluble pellet was re-suspended in $3 \mathrm{M}$ guanidine $\mathrm{HCl}$ for $4 \mathrm{~h}$ and centrifuged, and the supernatant was collected (i.e., insoluble $A \beta$ ). The level of $A \beta$ was determined using $A \beta 40$ and $A \beta 42$ enzyme-linked immunosorbent assay (ELISA) kits (Life Technologies, Carlsbad, CA, USA). The absorbance was measured at $450 \mathrm{~nm}$ using a TECAN plate reader (Sunrise, UK).

\subsection{Histological Analysis}

Liver and epididymal fat tissues were post fixed in $4 \%$ formaldehyde at $4{ }^{\circ} \mathrm{C}$ overnight. Paraffin embedded epididymalfat tissues sections $(5 \mu \mathrm{m})$ were stained with HE. Representative images of HE-stained sections were shown. The size of adipocyte was measured by Image J Software (National Institutes of Health, Bethesda, MD, USA).

\subsection{Senile Plaques Staining and Immunohistochemistry}

Senile plaques were stained with $0.01 \%$ BSB as previously described $[3,36]$. To analyze the activation of plaque associated astrocyte and microglia, BSB-stained brain sections were further incubated with primary antibodies (i.e., mouse anti-GFAP antibody (1:500, Millipore, Temecula, CA, USA) or goat anti-Iba- 1 antibody (1:300, abcam)) at $4{ }^{\circ} \mathrm{C}$ overnight; washed with PBS; incubated with fluorescein isothiocyanate-donkey anti-mouse IgG and Alexa Fluor 647-donkey anti-goat IgG (1:300, Jackson ImmunoResearch, West Grove, PA, USA) for $2 \mathrm{~h}$. Slice was mounted with Aqua Poly/Mount (Polysciences, Inc., Warrington, PA, USA). Fluorescent images of BSB staining were taken using a Zeiss LSM 780 confocal microscope (Carl Zeiss Microscopy, Jena, Germany).

\subsection{Plaque Quantification}

Plaque quantification was performed in 11 z-stacked images compiled with maximum intensity projection spanning $10 \mu \mathrm{m}$. The number and size of plaques were determined from the images of $20 \times$ and $40 \times$ magnification, respectively. The size of senile plaques was measured by Image software. Threshold of Images were set by fluorescence at 20-255 and size at $>30 \mu \mathrm{m}^{2}$. The images were converted to binary images for quantification. Plaque diameter was measured as the greatest linear distance between any two points on the perimeter (Feret's diameter). Two serial sections including 
the middle region of the hippocampus ( -1.58 to $-1.94 \mathrm{~mm}$ relative to bregma) were analyzed for each mouse.

\subsection{Quantification of GFAP Intensity Surronding Plaque and Plaque-Associated Iba-1 Intensity}

Fluorescent images co-staining with GFAP and BSB at $40 \times$ magnification were used for GFAP quantification. The relative fluorescence intensity of GFAP in the vicinity of plaques was quantified using Metamorph software. None plaque associated area with threshold level 30-255, without shade correction was used as reference region. Representative BSB-images were set as $10-\mu \mathrm{m}$ depth with maximal projection. Binary images were converted with threshold level 20-255. A circle surrounding plaques with diameter of 8 times the Feret's diameter of plaque was delimited and the immunoreactivity of GFAP in this circle area was determined.

Fluorescent images of Iba-1 immunostaining with BSB-stained senile plaques were taken at $40 \times$ magnification. The relative fluorescence intensity of plaque associated Iba- 1 was quantified using Metamorph software. None plaque associated area with threshold level 30-255, without shade correction was used as reference region.

The overlapping plaques were excluded from analysis. Two serial sections including the middle region of the hippocampus ( -1.58 to $-1.94 \mathrm{~mm}$ relative to the bregma) were analyzed for each mouse.

\subsection{Nesting Behavior}

Mice were individually housed for $5 \mathrm{~h}$, then a nestlet pressed-cotton square (Ancare, Canterbury, Kent, UK) was put into each cage $1 \mathrm{~h}$ before the dark cycle started. Nest construction was scored using a 5-point scaling system $16 \mathrm{~h}$ later [34]. Nest score of 1 to 5 indicates a $>90 \%,>60 \%,>30 \%,>10 \%$ and $<10 \%$ intact nestlet, respectively, and the nest reaching score 5 has an obvious crater. The duration required for constructing a nest reaching scored 5 was recorded with a recording interval for $2 \mathrm{~h}$.

\subsection{Statistical Analysis}

GraphPad Prism (GraphPad, San Diego, CA, USA) was used to perform statistical analysis. All values are mean \pm SEM. Statistical analyses were performed using unpaired Student's $t$-tests for two groups and one-way analysis of variance (ANOVA) followed by Tukey's honest significant difference (HSD) post hoc test for the groups bigger or equal to 3. Analysis of nesting behavior scores was performed using the non-parametric Kruskal-Wallis test followed by the Mann-Whitney $U$ test.

\section{Conclusions}

The results of this study support that APS may be used to ameliorate peripheral metabolic stress, vascular inflammation and neuroinflammation thereby promote AD-related pathology, although $A \beta$-related pathologies were not altered.

Acknowledgments: This work was supported by grants from the Ministry of Science and Technology (MOST-102-2320-B-077-003; MOST-103-2311-B-010-008; MOST-103-2320-B-077-004-MY3; MM10501-0274).

Author Contributions: Young-Ji Shiao and Huey-Jen Tsay wrote the manuscript. Hui-Kang Liu wrote the proposal and designed the manuscript. Yung-Cheng Huang, Chih-Wen Yeh and Chien-Hung Lin performed the experiment. Yung-Cheng Huang conducted data analysis. Mei-Kuang Lu performed the characterization of APS. All authors read and approved the final manuscript.

Conflicts of Interest: The authors declare no conflict of interest. 


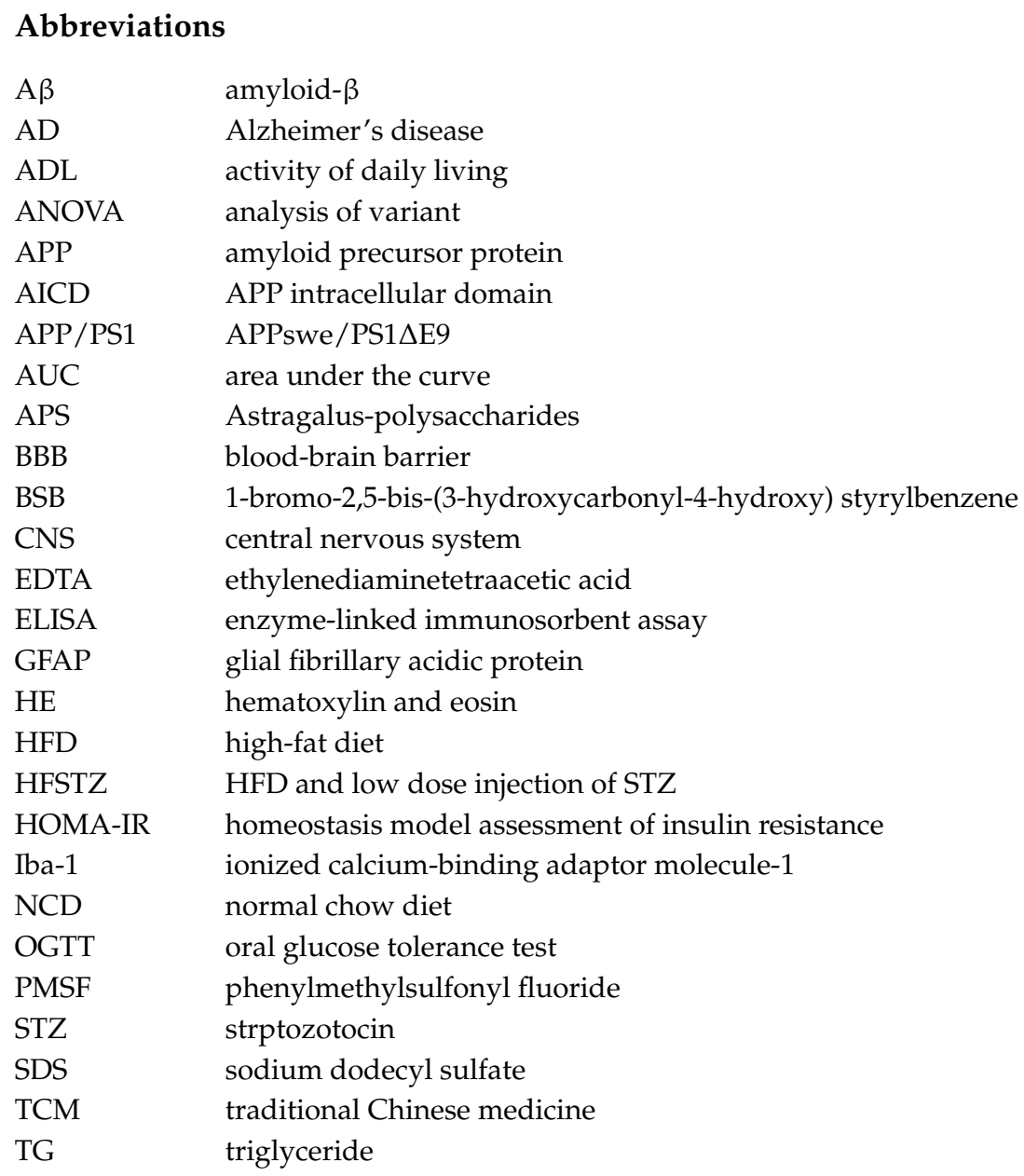

\section{References}

1. De la Monte, S.M. Type 3 diabetes is sporadic Alzheimer's disease: Mini-review. Eur. Neuropsychopharmacol. 2014, 24, 1954-1960. [CrossRef] [PubMed]

2. Block, M.L.; Zecca, L.; Hong, J.S. Microglia-mediated neurotoxicity: Uncovering the molecular mechanisms. Nat. Rev. Neurosci. 2007, 8, 57-69. [CrossRef] [PubMed]

3. Yeh, C.W.; Yeh, S.H.; Shie, F.S.; Lai, W.S.; Liu, H.K.; Tzeng, T.T.; Tsay, H.J.; Shiao, Y.J. Impaired cognition and cerebral glucose regulation are associated with astrocyte activation in the parenchyma of metabolically stressed APPswe/PS1dE9 mice. Neurobiol. Aging 2015, 36, 2984-2994. [CrossRef] [PubMed]

4. Shie, F.S.; Shiao, Y.J.; Yeh, C.W.; Lin, C.H.; Tzeng, T.T.; Hsu, H.C.; Huang, F.L.; Tsay, H.J.; Liu, H.K. Obesity and Hepatic Steatosis Are Associated with Elevated Serum Amyloid Beta in Metabolically Stressed APPswe/PS1dE9 Mice. PLoS ONE 2015, 10, e0134531. [CrossRef] [PubMed]

5. Yeh, C.W.; Liu, H.K.; Lin, L.C.; Liou, K.T.; Huang, Y.C.; Lin, C.H.; Tzeng, T.T.; Shie, F.S.; Tsay, H.J.; Shiao, Y.J. Xuefu Zhuyu decoction ameliorates obesity, hepatic steatosis, neuroinflammation, amyloid deposition and cognition impairment in metabolically stressed APPswe/PS1dE9 mice. J. Ethnopharmacol. 2017, 209, 50-61. [CrossRef] [PubMed]

6. Zhao, L.H.; Ma, Z.X.; Zhu, J.; Yu, X.H.; Weng, D.P. Characterization of polysaccharide from Astragalus radix as the macrophage stimulator. Cell Immunol. 2011, 271, 329-334. [CrossRef] [PubMed]

7. Zhao, M.; Zhang, Z.F.; Ding, Y.; Wang, J.B.; Li, Y. Astragalus polysaccharide improves palmitate-induced insulin resistance by inhibiting PTP1B and NF-KB in C2C12 myotubes. Molecules 2012, 17, 7083-7092. [CrossRef] [PubMed]

8. Jin, M.; Zhao, K.; Huang, Q.; Shang, P. Structural features and biological activities of the polysaccharides from Astragalus membranaceus. Int. J. Biol. Macromol. 2014, 64, 257-266. [CrossRef] [PubMed] 
9. He, X.; Shu, J.; Xu, L.; Lu, C.; Lu, A. Inhibitory effect of Astragalus polysaccharides on lipopolysaccharide-induced TNF-a and IL-1 $\beta$ production in THP-1 cells. Molecules 2012, 17, 3155-3164. [CrossRef] [PubMed]

10. Li, X.T.; Zhang, Y.K.; Kuang, H.X.; Jin, F.X.; Liu, D.W.; Gao, M.B.; Liu, Z.; Xin, X.J. Mitochondrial protection and anti-aging activity of Astragalus polysaccharides and their potential mechanism. Int. J. Mol. Sci. 2012, 13, 1747-1761. [CrossRef] [PubMed]

11. Liu, M.; Wu, K.; Mao, X.; Wu, Y.; Ouyang, J. Astragalus polysaccharide improves insulin sensitivity in KKAy mice: Regulation of PKB/GLUT4 signaling in skeletal muscle. J. Ethnopharmacol. 2010, 127, 32-37. [CrossRef] [PubMed]

12. Wang, N.; Zhang, D.; Mao, X.; Zou, F.; Jin, H.; Ouyang, J. Astragalus polysaccharides decreased the expression of PTP1B through relieving ER stress induced activation of ATF6 in a rat model of type 2 diabetes. Mol. Cell. Endocrinol. 2009, 307, 89-98. [CrossRef] [PubMed]

13. Mao, X.Q.; Yu, F.; Wang, N.; Wu, Y.; Zou, F.; Wu, K.; Liu, M.; Ouyang, J.P. Hypoglycemic effectof polysaccharide enriched extract of Astragalus membranaceus in diet induced insulin resistant C57BL/6J mice and its potential mechanism. Phytomedicine 2009, 16, 416-425. [CrossRef] [PubMed]

14. Zhang, Y.W.; Wu, C.Y.; Cheng, J.T. Merit of Astragalus polysaccharide in the improvement of early diabetic nephropathy with an effect on mRNA expressions of NF-kappaBandIkappaB in renal cortex of streptozotoxin-induced diabetic rats. J. Ethnopharmacol. 2007, 114, 387-392. [CrossRef] [PubMed]

15. Liu, H.; Bai, J.; Weng, X.; Wang, T.; Li, M. Amelioration of insulin resistance in rat cells by Astragalus polysaccharides and associated mechanisms. Exp. Ther. Med. 2014, 7, 1599-1604. [CrossRef] [PubMed]

16. Torres-Lista, V.; Gimenez-Llort, L. Impairment of nesting behaviour in 3xTg-AD mice. Behav. Brain Res. 2013, 247, 153-157. [CrossRef] [PubMed]

17. Daulatzai, M.A. Cerebral hypoperfusion and glucose hypometabolism: Key pathophysiological modulators promote neurodegeneration, cognitive impairment, and Alzheimer's disease. J. Neurosci. Res. 2017, 95, 943-972. [CrossRef] [PubMed]

18. Ho, L.; Qin, W.; Pompl, P.N.; Xiang, Z.; Wang, J.; Zhao, Z.; Peng, Y.; Cambareri, G.; Rocher, A.; Mobbs, C.V.; et al. Diet-induced insulin resistance promotes amyloidosis in a transgenic mouse model of Alzheimer's disease. FASEB J. 2004, 18, 902-904. [CrossRef] [PubMed]

19. Matheson, P.J.; Franklin, G.A.; Hurt, R.T.; Downard, C.D.; Smith, J.W.; Garrison, R.N. Direct Peritoneal Resuscitation Improves Obesity-Induced Hepatic Dysfunction after Trauma. J. Am. Coll. Surg. 2012, 214, 517-528. [CrossRef] [PubMed]

20. Dun, C.; Liu, J.; Qiu, F.; Wu, X.; Wang, Y.; Zhao, Y.; Gu, P. Effects of Astragalus polysaccharides on memory impairment in a diabetic rat model. Neuropsychiatr. Dis. Treat. 2016, 12, 1617-1621. [CrossRef] [PubMed]

21. Wang, Y.R.; Wang, Q.H.; Zhang, T.; Liu, Y.H.; Yao, X.Q.; Zeng, F.; Li, J.; Zhou, F.Y.; Wang, L.; Yan, J.C.; et al. Associations Between Hepatic Functions and Plasma Amyloid-Beta Levels-Implications for the Capacity of Liver in Peripheral Amyloid-Beta Clearance. Mol. Neurobiol. 2017, 54, 2338-2344. [CrossRef] [PubMed]

22. Itagaki, S.; McGeer, P.L.; Akiyama, H.; Zhu, S.; Selkoe, D. Relationship of microglia and astrocytes to amyloid deposits of Alzheimer disease. J. Neuroimmunol. 1989, 24, 173-182. [CrossRef]

23. Han, R.; Tang, F.; Lu, M.; Xu, C.; Hu, J.; Mei, M.; Wang, H. Protective effects of Astragalus polysaccharides against endothelial dysfunction in hypertrophic rats induced by isoproterenol. Int. Immunopharmacol. 2016, 38, 306-312. [CrossRef] [PubMed]

24. Jiang, J.B.; Qiu, J.D.; Yang, L.H.; He, J.P.; Smith, G.W.; Li, H.Q. Therapeutic effects of astragalus polysaccharides on inflammation and synovial apoptosis in rats with adjuvant-induced arthritis. Int. J. Rheum. Dis. 2010, 13, 396-405. [CrossRef] [PubMed]

25. Huang, W.M.; Liang, Y.Q.; Tang, L.J.; Ding, Y.; Wang, X.H. Antioxidant and anti-inflammatory effects of Astragalus polysaccharide on EA.hy926 cells. Exp. Ther. Med. 2013, 6, 199-203. [CrossRef] [PubMed]

26. Lu, J.; Chen, X.; Zhang, Y.; Xu, J.; Zhang, L.; Li, Z.; Liu, W.; Ouyang, J.; Han, S.; He, X. Astragalus polysaccharide induces anti-inflammatory effects dependent on AMPK activity in palmitate-treated RAW264.7 cells. Int. J. Mol. Med. 2013, 31, 1463-1470. [CrossRef] [PubMed]

27. Liu, L.; Chen, S.; Xu, X.; Hou, B.; Mo, F. Astragalus polysaccharides combined with ibuprofen exhibit a therapeutic effect on septic rats via an anti-inflammatory cholinergic pathway. Exp. Ther. Med. 2017, 14, 3127-3130. [CrossRef] [PubMed] 
28. Allaman, I.; Belanger, M.; Magistretti, P.J. Astrocyte-neuron metabolic relationships: For better and for worse. Trends Neurosci. 2011, 34, 76-87. [CrossRef] [PubMed]

29. Thal, D.R. The role of astrocytes in amyloid beta-protein toxicity and clearance. Exp. Neurol. 2012, 236, 1-5. [CrossRef] [PubMed]

30. Furman, J.L.; Sama, D.M.; Gant, J.C.; Beckett, T.L.; Murphy, M.P.; Bachstetter, A.D.; Van Eldik, L.J.; Norris, C.M. Targeting astrocytes ameliorates neurologic changes in a mouse model of Alzheimer's disease. J. Neurosci. 2012, 32, 16129-16140. [CrossRef] [PubMed]

31. Yin, Z.; Raj, D.; Saiepour, N.; Van Dam, D.; Brouwer, N.; Holtman, I.R.; Eggen, B.J.L.; Möller, T.; Tamm, J.A.; Abdourahman, A.; et al. Immune hyperreactivity of A $\beta$ plaque-associated microglia in Alzheimer's disease. Neurobiol. Aging 2017, 55, 115-122. [CrossRef] [PubMed]

32. Baik, S.H.; Kang, S.; Son, S.M.; Mook-Jung, I. Microglia contributes to plaque growth by cell death due to uptake of amyloid $\beta$ in the brain of Alzheimer's disease mouse model. Glia 2016, 64, 2274-2290. [CrossRef] [PubMed]

33. Deacon, R.M.; Croucher, A.; Rawlins, J.N. Hippocampal cytotoxic lesion effects on species-typical behaviours in mice. Behav. Brain Res. 2002, 132, 203-213. [CrossRef]

34. Deacon, R.M. Housing, husbandry and handling of rodents for behavioral experiments. Nat. Protoc. 2006, 1, 936-946. [CrossRef] [PubMed]

35. Jankowsky, J.L.; Fadale, D.J.; Anderson, J.; Xu, G.M.; Gonzales, V.; Jenkins, N.A.; Copeland, N.G.; Lee, M.K.; Younkin, L.H.; Wagner, S.L.; et al. Mutant presenilins specifically elevate the levels of the 42 residue beta-amyloid peptide in vivo: Evidence for augmentation of a 42-specific gamma secretase. Hum. Mol. Genet. 2004, 13, 159-170. [CrossRef] [PubMed]

36. Skovronsky, D.M.; Zhang, B.; Kung, M.P.; Kung, H.F.; Trojanowski, J.Q.; Lee, V.M. In vivo detection of amyloid plaques in a mouse model of Alzheimer's disease. Proc. Natl. Acad. Sci. USA 2000, 97, 7609-7614. [CrossRef] [PubMed]

(C) 2017 by the authors. Licensee MDPI, Basel, Switzerland. This article is an open access article distributed under the terms and conditions of the Creative Commons Attribution (CC BY) license (http:/ / creativecommons.org/licenses/by/4.0/). 